\title{
PROPENSITY FOR EXPERIENCING FLOW: THE ROLES OF COGNITIVE
}

FLEXIBILITYAND MINDFULNESS

\section{by}

\section{Bryan A. Moore}

A thesis in partial fulfillment of the requirements for the degree of MASTER OF ARTS

Department of Psychology

Towson University

May 2012 


\section{TOWSON UNIVERSITY COLLEGE OF GRADUATE STUDIES AND RESEARCH THESIS APPROVAL PAGE}

This is to certify that the thesis prepared by ___ Bryan A. Moore entitled Propensity for Experiencing Flow: The Roles of Cognitive Flexibility and Mindfulness has been approved by the thesis committee as satisfactorily completing the thesis requirements for the degree_Master of Arts_.

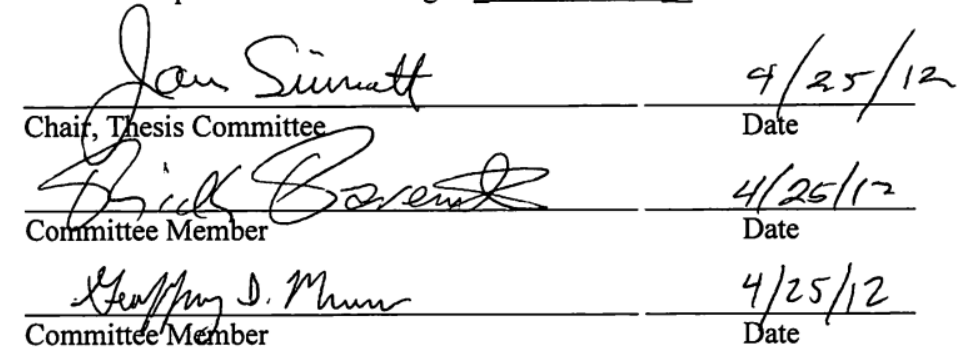

\begin{tabular}{ll}
\hline Committee Member & Date \\
\hline Committee Member & Date \\
\hline Committee Member & Date
\end{tabular}

$\overline{\text { Associate Dean, College of Graduate Studies and Research Date }}$ 


\begin{abstract}
Propensity for Experiencing Flow: The Roles of Cognitive Flexibility and Mindfulness Bryan A. Moore

The current study examined cognitive skills related to flow disposition. College students from Towson University (64 women and 41 men, $M_{\text {age }}=20$ years, age range 18-28 years) were recruited from undergraduate classes. Participants completed a survey that contained the Cognitive and Affective Mindfulness Scale-Revised (CAMS-R; Feldman et al. 2007), the Cognitive Flexibility Scale (CFS; Martin \& Ruben, 1995), the Dispositional Flow Scale-2 General (DFS2; Jackson \& Eklund, 2002), and demographic questions. They were also asked if they had ever practiced mindfulness meditation. A hierarchical regression analysis showed that when demographic variables and history of mindfulness meditation were held constant cognitive flexibility and mindfulness were good predictors of flow disposition, $R^{2}=.42$, adjusted $R^{2}=.39, F(5,99)=14.30, p<.001$. Conclusions and implications are discussed.
\end{abstract}




\section{TABLE OF CONTENTS}

INTRODUCTION

LITERATURE REVIEW 4

$\begin{array}{ll}\text { METHOD } & 16\end{array}$

$\begin{array}{ll}\text { RESULTS } & 19\end{array}$

$\begin{array}{ll}\text { DISCUSSION } & 21\end{array}$

$\begin{array}{ll}\text { APPENDECIES } & 25\end{array}$

$\begin{array}{ll}\text { APPENDIX A - IRB Approval Form } & 26\end{array}$

$\begin{array}{ll}\text { APPENDIX B - Consent Form } & 27\end{array}$

$\begin{array}{ll}\text { REFERENCES } & 28\end{array}$

$\begin{array}{ll}\text { CURRICULUM VITA } & 34\end{array}$ 


\section{INTRODUCTION}

The field of modern psychology has produced an extensive body of literature related to happiness and well-being. Although this subject matter has appeared in philosophical, religious, and artistic work for thousands of years, much of the recent psychological literature is unique in that it incorporates rigorously collected empirical evidence to support or repudiate theories and suppositions. As the strength and breadth of this evidence grows, new concepts arise; one such concept is that of flow.

In the 1970's, a researcher named Mihaly Csikszentmihalyi, who was conducting research on creativity and creative processes (Csikszentmihalyi \& Getzels, 1970, 1971), conceptualized a type of positive experience that characterizes the engagement in intrinsically rewarding activities (Csikszentmihayli, 1990). Csikszentmihalyi (2000b) noticed that people sometimes have a heightened attention to activities and that they are driven to participate in these activities even when demands such as hunger or fatigue set in. He proposed that there is a motivation toward the enthrallment involved, and that the motivation is common to all people. This state of enthrallment and ordered consciousness is called flow (Csikszentmihalyi, 2000b, 1990).

People can experience flow during a number of different activities; current research has explored flow during athletics (Kee \& Wang, 2008), musical performance (Fritz \& Avsec, 2007), computer gaming (Chou \& Ting, 2003; Scoresby \& Shelton, 2011), and even military combat (Harari, 2008). The types of activities that induce flow may differ, in part, because one of the requirements of flow is simply that the challenge level of the activity is balanced with the skill level possessed by the individual (Csikszentmihayli, 1990, 2000b). In addition to a balanced skill/challenge ratio, 
Csikszentmihayli (1990) proposed that there are eight other experiential components of flow; these include clear goals, clear and immediate feedback on performance, a sense of control, time transformation, a loss of self-consciousness, immersion of action and awareness, a sense of intrinsic value in the experience, and a high level of concentration.

Flow state has been described in terms of intrinsic motivation (Eccles \& Wigfield, 2002; Waterman, Schwartz, \& Conti, 2008) and happiness (Csikszentmihayli, 1990; Waterman, 1993). With regard to happiness, Waterman (1993) has proposed that flow states are manifestations of personal expressiveness, or eudaimonia. They may be signifiers of self-realization and a global sense of happiness, as opposed to more superficial, or hedonically enjoyed, experiences of happiness (Waterman, 1993). See Ryan and Deci (2001) for a review of eudaimonia and hedonic enjoyment.

In a different vein, Csikszentmihayli (1990) has portrayed flow state as the optimal experience. This may be the case, but others have posited that flow is simply one type of optimal experience (Privette, 1983) and that intrinsic motivation also occurs for other types of experiences (Reiss, 2000). Although there is some debate regarding the magnitude of flow as optimal experience, there appears to be a consensus that flow state can be a significant source of well-being (e.g. Csikszentmihayli, 1990; Fritz \& Avsec, 2007; Harari, 2008; Moneta \& Csikszentmihalyi, 1996; Myers \& Diener, 1995; Payne, Jackson, Noh, \& Stine-Morrow, 2011; Waterman, 2005).

As an experience related to well-being and activity engagement, flow, and flow research, may have applications in advancing clinical interventions (Feeney, 1996) and workplace productivity (Martin, 2004). In an attempt to increase knowledge in these domains, the current study explores some of the cognitive skills that may be related to 
individuals' propensity for experiencing flow. More specifically, I will examine mindfulness and cognitive flexibility as skills associated with flow disposition.

Currently, there is little research on the cognitive skills related to flow disposition in the general population. Csikszentmihayli (1990) has proposed that people who are more likely to experience flow may have a certain personality type, i.e. the autotelic personality, which is primarily characterized by a need for cognition and engagement. However, there is little empirical research that examines the individual differences in why some people may be more inclined to experience flow. 


\section{LITERATURE REVIEW}

\section{Flow measurement}

One of the earliest methods for examining flow was the Experience Sampling Method (ESM; Larson \& Csikszentmihalyi, 1983). The ESM entails research participants being notified by a pager or stopwatch at certain points throughout the day to complete open-ended questions about their experience and what activities they are doing. Recently, some studies on flow have utilized other qualitative methods such as journals and interviews (Wright, Sadlo, \& Stew, 2006, 2007), but the majority of current research uses self-report surveys to measure flow (e.g. Fritz \& Avsec, 2007; Kee \& Wang, 2008;

Payne, Jackson, Noh, \& Stine-Morrow, 2011; Stavrou, Jackson, Zervas, \& Karteroliotis, 2007; Yuan, Hu, \& Wang, 2009). One such survey is the Dispositional Flow Scale (DFS; Jackson \& Marsh, 1996).

Jackson and Marsh (1996) developed the DFS to measure individuals' dispositions toward flow in physical activities. The scale is based on Csikszentmihayli's (1990) nine dimensions of flow previously discussed. The thirty six item self-report uses a 5-point Likert scale, ranging from $1=$ "never" to $5=$ "always." It contains items such as "I do things spontaneously and automatically without having to think," "I am completely focused on the task at hand," and "I have a feeling of total control over what I am doing." Confirmatory factor analyses have supported both a nine-factor model as well as a single, global, flow model for this scale (Jackson \& Eklund, 2002; Jackson \& Marsh, 1996). The DFS was modified in a subsequent version, the Dispositional Flow Scale-2 (DFS2; Jackson \& Eklund, 2002), to address wording problems and some weaknesses in DFS subscale factor loadings. The revised version has shown psychometric worth in studies 
analyzing both physical activities (Jackson \& Eklund, 2002; Kee \& Wang, 2008) and non-physical activities (Wang, Khoo, Liu, \& Divaharan, 2008; Wang, Liu, \& Khoo, 2009). It has shown good reliability in at least two samples, $\alpha=.78$ and $\alpha=.86$ (Jackson \& Eklund, 2002). Kee and Wang (2008) used the DFS2 to analyze the relationship between flow disposition and the state of mindfulness. The authors report that their results suggest that those who are more mindful are more likely to experience flow.

\section{Mindfulness}

In the clinical and medical fields, mindfulness has been gaining in popularity for decades (Bishop, 2002). In 2004, a panel of North American psychologists produced a detailed description of mindfulness in an attempt to establish a widely recognized operational definition of the construct - something that did not exist in the academic world at that time (Bishop et al., 2004). Based on past descriptions and studies of mindfulness, the researchers proposed a two component model concerning 1) the self regulation of attention, and 2) the orientation to experience.

Within this model, the self regulation of attention refers to one's ability to manipulate his or her attentional processes. It includes an ability to sustain focused attention over time and the ability to elicit present moment awareness. Also, Bishop et al. (2004) noted that being cognitively flexible and having the capacity to switch between mental events is an important aspect of the self regulation of attention in mindfulness.

The second component of Bishop et al.'s (2004) operational definition, orientation to experience, entails a curiosity and acceptance of one's thoughts, feelings, and emotions. If someone is mindful, they are oriented to their experience in an open and 
non-judgmental way. This openness is also coupled with an effort to observe and investigate one's internal experience.

\section{Mindfulness and flow}

The two component model proposed by Bishop et al. (2004) characterizes mindfulness as a state or psychological process. Mindfulness is also likened to a skill that can be cultivated (Bishop et al., 2004) and some meditation practices can develop this mindfulness skill (Bishop et al., 2004; Jensen, Vangkilde, Frokjaer, \& Hasselbalch, 2011; Kabat-Zinn, 2005). A growing body of research suggests that, in addition to increasing mindfulness, mindfulness training may enhance many of the attentional processes that underlie the state.

In a study conducted by van den Hurk (2010) mindfulness meditation and attention were explored. The researcher measured differences in attention processing performance between mindfulness meditators and a control group. The results show that the group of mindfulness meditators was more accurate on an attention network computer task when compared to controls. Although the meditators performed slower as a whole, they were more accurate when matched on response time with controls. This result led the researchers to propose that mindfulness meditators may be more efficient in their attentional processing.

Chan and Woollacott (2007) have shown that mindfulness meditators experience less interference on Stroop tasks, and an experiment conducted by Tang, Ma, Wang, Fan, Feng, Lu, et al. (2007) suggests that meditation training can increase executive attention functionality on attention tasks. However, Jensen et al. (2011) have shown that attentional effort may confound the results of many of the studies that examine the 
relationship between mindfulness training and attention processing. Many studies do not account for a possible increase in test effort on attention measures in mindfulness-trained participants (Jensen et al., 2011). For example, people who are trained in mindful attention techniques may simply put forth more effort in post-training attention measures. Regardless, Jensen et. al. (2011) demonstrated that mindfulness training does appear to enhance mindfulness and some attentional processes when performance rewards are accounted for.

Both theoretical and empirical literature imply that the self regulation of attention is an aspect of mindfulness. Similarly, some research now suggests that attention regulation may also be related to flow. For example, Cermakova, Moneta, and Spada (2010) investigated the relationship between flow, approaches to studying, and attention control. The researchers administered the Dispositional Flow Scale-2 (Jackson \& Eklund, 2002, 2004) to measure studying-related flow disposition and the Attentional Control Scale (ACS; Derryberry \& Reed, 2002) to measure attention regulation in a sample of 240 university students in the U.K. The research showed that flow disposition was highly correlated with attention control, $\mathrm{r}=.55, p<0.01$. This relationship between attention control and flow disposition appears to be consistent with accounts of flow (e.g. Csikszentmihalyi, 1990). Because flow entails a high level of concentrated attention on an activity, it may be that attentional control is a skill that allows for this intense, uninterrupted, focus.

Because flow state and mindfulness both appear to entail the self-regulation of attention, it is not unexpected that there is emerging empirical support that people who have a high disposition toward flow state tend to be more mindful (Bernier, Thienot, 
Codron, \& Fournier, 2009; Kee \& Wang, 2008). Wright, Sadlo, and Stew (2006) have found evidence from interviews that flow state and mindfulness are similar states in that they both entail living in the present moment and being free from worry. However, they can differ in the effort involved and the perception of time. Wright et al. (2006) have even proposed that, because flow and mindfulness are so similar, that they may be different stages along an experiential continuum as opposed to all-or-nothing phenomena. Although this theory holds promise, most research in this field is conducted under the assumption that they are distinct experiences (e.g. Bernier et al., 2009; Kee \& Wang, 2008).

A study conducted by Kee and Wang (2008) examined the relationship between flow disposition and mindfulness in a sample of college athletes from a university in Singapore. The researchers were primarily interested in how present moment focus and mental skills adoption related to flow disposition in athletes. They administered the Dispositional Flow Scale-2 (Jackson \& Eklund, 2004) and the Mindfulness/Mindlessness Scale (MMS; Bodner \& Langer, 2001) to a group of 182 students. A cluster analysis was used to group participants. A high mindfulness group was found to score significantly higher on flow disposition when compared to the other, lower mindfulness, clusters. This suggests that athletes with a propensity to be more mindful are also more inclined to experience flow states.

One criticism of this study is that the mindfulness scale used has not shown established validity in the literature. Kee and Wang (2008) cite Bodner and Langer (2001) as basing the scale on a four component model of mindfulness: novelty seeking, novelty producing, flexibility, and engagement. The authors note that Bonder and Langer 
(2001) base their scale on Bishop et al.'s (2004) operational definition of mindfulness.

However, the scale does not appear to measure mindfulness, per se, but rather tendencies that predict, or that may be related to, mindfulness.

\section{Mindfulness measures}

Although mindfulness is commonly characterized as a state (Bishop et al., 2004;

Kabat-Zinn, 2005; Langer, 1992; Shapiro, Carlson, Astin, \& Freedman, 2006), assessments used to measure it have primarily focused on the more trait-like, or dispositional, aspect of it. Two of the earliest self-report measures of mindfulness were the Cognitive and Affective Mindfulness Scale (CAMS; Kumar, 2005 as cited in Feldman, Hayes, Kumar, Greeson, \& Laurenceau, 2007) and the amended version, the Cognitive and Affective Mindfulness Scale-Revised (CAMS-R; Feldman et al., 2007).

The theory behind the CAMS-R was based on work by Kabat-Zinn $(2003 ; 2005)$ and Bishop et al. (2004). Feldman et al. (2007) expanded Bishop et al.'s (2004) two part model of mindfulness to a four component model. According to Feldman et al. (2004), mindfulness includes 1) the ability to regulate attention, 2) an orientation to present or immediate experience, 3) awareness of experience, and 4) an attitude of acceptance or non-judgment towards experience.

The CAMS-R is a twelve item self-report scale that measures mindfulness as a single factor. According to Feldman et al. (2004) it has shown an acceptable level of internal consistency in two samples $(\alpha=.74 ; \alpha=.77)$, and the scale has shown adequate convergent validity; Feldman et al. (2004) has demonstrated significant positive correlations between the CAMS-R and two other measures of mindfulness, the Freiburg

Mindfulness Inventory (FMI; Buchheld, Grossman, \& Walach, 2002), r = .66, p < 0.001, 
and the Mindful Attention Awareness Scale (MAAS; Brown \& Ryan, 2003), $\mathrm{r}=.51, \mathrm{p}<$ 0.001 .

According to Feldman et al. (2004), no other mindfulness measures were available at the time of the original CAMS creation. Since the creation of the CAMS and the subsequent CAMS-R, a number of mindfulness self-report scales have been developed and reported in the literature: the Freiburg Mindfulness Inventory (Buchheld, Grossman, \& Walach, 2002), Mindful Attention Awareness Scale (MAAS; Brown \& Ryan, 2003), the Kentucky Inventory of Mindfulness Skills (Baer, Smith, \& Allen, 2004), the Langer Mindfulness Scale (Bonder \& Langer, 2001), and the Southampton Mindfulness Questionnaire (MQ; Chadwick, Hember, Mead, Lilley, \& Dagnan, 2005). Baer, Smith, Hopkins, Krietemeyer, and Toney (2006) examined five of these scales: the MASS, FMI, KIMS, CAMS, and MQ. Baer et al. (2006) administered a single questionnaire, which contained all five of the mindfulness scales, to a sample of 613 US college students. The results showed that each scale in the questionnaire significantly correlated with the others. In addition, the researchers investigated the criterion validity of the scales further and found that each scale followed predicted correlations with a number of related scales, including the Brief Symptom Inventory (BSI; Derogatis, 1992), the Scale of Dissociative Activities (SODAS; Mayer \& Farmer, 2003), and the Difficulties in Emotion Regulation Scale (DERS; Gratz \& Roemer, 2004).

Baer et al. (2006) was also interested in discovering commonalties between the scales insofar as the scales shared factors, or facets, of mindfulness. They conducted an exploratory factor analysis and uncovered five factors between the five scales. Four of the five factors are nearly identical to ones included in the KIMS (Baer, Smith, \& Allen, 
2004), although another factor, related to a non-reactive stance toward internal experience, also emerged.

Each of the five mindfulness factors showed good internal consistency and adequate reliability levels: nonreactivity $=.75$, observing $=.75$, acting with awareness $=$ .87 , describing $=.91$, and nonjudgement $=.87$. However, only modest correlations existed between the five facets, and a confirmatory factory analysis showed a poor fit to model with mindfulness as a single, global, construct.

A shortcoming of Baer et al.'s (2006) five factor model is that it does not appear to entail a factor that explicitly measures the self regulation of attention, an important component of mindfulness (Bishop et al., 2004; Shapiro et al., 2006). The KIMS (Baer, Smith, \& Allen, 2004), the scale for which the five factor model nearly mimicked, also lacks a self regulation component.

The FMI (Buchheld, Grossman, \& Walach, 2002), another scale included in the analysis, appears to be an adequate measure of mindfulness. However, a validation study showed that the researchers measured mindfulness after meditation retreats (Walach et al., 2006), and it is unclear as to whether the scale is an appropriate measure of mindfulness disposition, as opposed to state mindfulness.

The MASS (Brown \& Ryan, 2003), on the other hand, adequately measures the cognitive components of mindfulness, but it lacks the dimensions of objectivity and nonjudgment that are proposed by Bishop et al. (2004). A criticism of the Southampton Mindfulness Questionnaire (Chadwick et al., 2005) is that it explicitly measures mindfulness in the face of distressing thoughts and difficult cognitions. 
In Kee and Wang's (2008) study that examined the relationship between mindfulness and flow, the scale that they used to measure mindfulness (MMS) was not included in Baer et al.'s (2006) analysis. One way in which this scale was different from the scales analyzed by Baer et al. (2006) was that it included a cognitive flexibility subscale. Though cognitive flexibility has not been used as a sub-scale of mindfulness in the previously reviewed scales, some researchers have proposed that cognitive flexibility is an aspect of mindfulness (Bishop et al., 2004; Feldman et al., 2007; Frewen, 2008; Moore \& Malinowski, 2009).

\section{Cognitive flexibility}

Cognitive flexibility has been defined in many ways and from a number of different perspectives (Murray, Sujan, Hirt, \& Sujan, 1990). In general, most definitions include at least one of three factors: 1) the ability to adapt to change (Cañas, Quesada, Antolí, \& Fajardo, 2003; Dennis \& Vander Wal, 2010), 2) the ability think of a variety of categories and concepts (Hirt, Devers, \& McCrea, 2008; Murray, 1990) and 3) the ability to perceive multiple perspectives or thoughts (Bishop et al., 2004; Feldman et al., 2007). Although Kee and Wang (2008) measured cognitive flexibility as a sub-scale of mindfulness, other scales have been developed that measure cognitive flexibility as an independent construct.

For example, Martin and Ruben (1995) created the Cognitive Flexibility Scale (CFS). These researchers were interested in measuring cognitive flexibility as a global skill that may be a precursor to communication flexibility (Martin \& Rubin, 1995). The CFS is based on the assumptions that cognitive flexibility is 1) awareness that multiple 
options and alternatives exist in any given situation, 2) willingness to be flexible and adapt to a situation, and 3) self-efficacy in being flexible and adaptive.

In college student samples, the CFS has shown good reliability and validity across studies. It has shown positive correlations with the Communication Flexibility Scale (Martin \& Rubin, 1995), $\mathrm{r}=.53, p<0.05$, (Martin \& Rubin, 1995), the Argumentiveness Scale (Infante \& Rancer, 1982), $\mathrm{r}=.35, p<.01$, (Martin, Anderson, \& Thweatt, 1998), and the Decision Making Collaboration Scale (Anderson, Martin, \& Infante, 1998), r = $.47, p<.001$ (Dunleavy, 2006). The CFS has also shown negative correlations with the Rigidity of Attitudes Regarding Personal Habits Scale (Meresko, Rubin, Shontz, Morrow, 1954), $\mathrm{r}=-.16, p<0.05$ (Martin \& Rubin, 1995) and dogmatism, $\mathrm{r}=-.60, p<.01$ (Martin, Staggers, \& Anderson, 2011). Cronbach's alpha levels have repeatedly exceeded the .70 level (e.g. Dunleavy, 2006, Martin et al., 1998; Martin \& Rubin, 1995; Martin et al., 2011).

A more recently developed scale, the Cognitive Flexibility Inventory (Dennis \& Vander Wal, 2010) has also shown value. This scale was created to measure flexibility in an individual's ability to replace maladaptive thoughts with more beneficial, adaptive, ones. The CFI was created, primarily, as a clinical inventory or research tool. One criticism of the scale is that two of its components focus on an individual's ability for perspective-taking (i.e. "I am good at putting myself in other's shoes," and "I try to think about things from another person's point of view.") With this there is an implicit assumption that perspective taking is a form of cognitive flexibility. Although this scale appears to be sufficient for clinically assessing individuals' flexibility in difficult life 
situations, it is questionable as to whether it is an adequate measure of a more general cognitive flexibility.

However, the Cognitive Flexibility Scale, which has shown a positive correlation with the Cognitive Flexibility Inventory, $r=.75, \mathrm{p}<.001$ (Dennis \& Vander Wal, 2010), also contains a social component. One criticism of the CFS is that two of the twelve questions are explicitly related to interpersonal communication (i.e. "I can communicate an idea in many different ways" and "I am willing to listen and consider alternatives for handling a problem"). Otherwise, the CFS appears to be an adequate measure of general cognitive flexibility and its validity is more established in the literature when compared to the CFI.

As it has been proposed that cognitive flexibility is related to mindfulness (Feldman et al., 2007; Frewen, 2008; Moore \& Malinowski, 2009), it may also be the case that the cognitive flexibility is also related to flow. This relationship may exist because of the demands inherent in maintaining a flow state. In flow, skills are required to meet challenges of an activity (Csikszentmihalyi, 1990) and cognitive flexibility may allow an individual to adapt to the challenges and respond creatively in order to meet the activity's demands. If this is the case, then those with greater cognitive flexibility may have a higher disposition toward flow because they would possess one of the cognitive abilities that enables the experience.

\section{The current study}

The current study examines the relationships between cognitive flexibility, mindfulness, and flow. Kee and Wang (2008) previously examined these three constructs 
in college athletes. However, the current study addresses some weaknesses of Kee and Wang's (2008) study.

The mindfulness scale used by Kee and Wang (2008) included a cognitive flexibility sub-scale as part of the mindfulness construct, and this sub-scale was not shown to have adequate internal consistency. In addition, the mindfulness scale used has not shown strong validity in the literature. In addition, the sample only consisted of college athletes and I am concerned with college students in general. To address these issues, I administered cognitive flexibility and mindfulness scales, which have more established validity, to a general sample of college students in order to examine the relationships with flow disposition.

Because the self-regulation of attention is a skill that is shared by both mindfulness and flow (Bishop et al., 2004; Cermakova, Moneta, \& Spada, 2010) and that attentional control practice may increase flow (Clark, 2002), I hypothesized that mindfulness will positively correlate with flow disposition. I also hypothesize that cognitive flexibility and mindfulness will prove to be good predictors of flow disposition. 


\section{METHOD}

\section{Participants}

College students from Towson University in Towson, Maryland (64 women and 41 men, $M_{\text {age }}=20$ years, age range $18-28$ years) were recruited from undergraduate psychology and research methods classes. Forty-two percent were freshman, 21\% were sophomores, $17 \%$ were juniors, $18 \%$ were seniors, and $2 \%$ were post-baccalaureate or non-degree seeking students. Seventy-one percent were white or Caucasian, $14 \%$ were black or African American, 5\% were bi-racial or multi-ethnic, 4\% were Hispanic, 1\% were Asian, $1 \%$ were unknown or did not want to report their race or ethnicity, and $3 \%$ were other. Thirty-four percent reported having previously practiced mindfulness meditation and $66 \%$ reported that they had never practiced mindfulness meditation. Two of the three classes surveyed were offered extra credit for participation. To ensure that extra credit did not influence responses a multiple regression analysis was computed to determine if the two groups, those offered extra credit and those offered no extra credit, were different. Flow disposition, mindfulness, and cognitive flexibility scores did not predict class membership.

\section{Questionnaire Materials}

Flow disposition. The Dispositional Flow Scale-2 General (DFS2; Jackson \& Eklund, 2002) was used to measure participants' propensity toward flow in specific activities. The ratings for the short DFS-2 fall on a 5-point Likert scale, ranging from 1 (never) to 5 (always). I included additional statements before the instructions so that the activities measured would not be limited in type: 
The next part of the survey deals with a psychological state known as "Flow." Flow is an optimal experience that some people have when they are intensely involved, or engaged, in doing something that is fun to do. It is often known as "being in the zone," and it can occur during a number of different activities. Below you will read statements that express how people sometimes describe these experiences.

Try now to remember a single activity that you like to do, one that you greatly enjoy or find extremely rewarding. This can be any type of activity. Some examples may include athletics, playing music, creating art, playing video games, etc. Please think of one type of activity that you enjoy.

Mindfulness. The Cognitive and Affective Mindfulness Scale-Revised (CAMSR; Feldman et al. 2007) was used to measure dispositions toward mindfulness. The CAMS-R contains twelve items. Examples include "I am easily distracted," "I am able to focus on the present moment," and "I try to notice my thoughts without judging them." Participants were asked to rate their responses on a four-point Likert scale with the following options: 1 (Rarely/Not at all), 2 (Sometimes), 3 (Often), or 4 (Almost always). Numbers 2, 6, and 7 of the CAMS-R were reverse scored.

Cognitive flexibility. The Cognitive Flexibility Scale (CFS; Martin \& Ruben, 1995) was used to measure participants' level of cognitive flexibility. Responses were made on a six-point Likert scale, ranging from 1 (strongly disagree) to 6 (strongly agree). The CFS contains items such as "In any given situation, I am able to act appropriately," "I seldom have choices when deciding how to behave," and "I can find workable 
solutions to seemingly unsolvable problems." Numbers 2, 3, 5, and 10 of the CFS were reverse scored.

\section{Procedure}

Participants in two undergraduate psychology classes and one research methods class were told by their instructor that a graduate student would be conducting a survey study in their class. The graduate student researcher then reminded the students that participation is optional and that they will not experience a penalty if they chose to not participate. He instructed the students to complete all sections of the survey and to raise their hand if they had any questions.

The researcher handed-out an informed consent form and the questionnaire survey packet, which included the DFS2, CAMS-R, CFS, and demographic questions. Participants were instructed to read the informed consent form, sign it if they were willing to participate, and then complete the survey. They were instructed to bring the informed consent form and survey packet to the front of the class when they were finished or to raise their hand when they were done. 


\section{RESULTS}

Eight surveys were not included in the analysis because one or more items were left blank. Additionally, there were two cases where two responses were selected for a single item on surveys. The two response scores were averaged to get those items' scores.

Participants were free to choose whatever type of activity that they wanted for the flow disposition questionnaire; common responses were athletics/sports, dance, creating art, reading, academics, video gaming, and music performance.

The scales showed good reliability. The Cronbach's alpha level for the CAMS-R was .82, for the CFS it was .77, and for the DFS2 it was .96.

A Pearson's product correlation analysis indicated that history of mindfulness meditation had low correlations with age, $\mathrm{r}(105)=.20, p<0.05$, and cognitive flexibility, $\mathrm{r}(105)=.20, p<0.05$. Cognitive flexibility also showed high, significant, correlations with mindfulness $\mathrm{r}(105)=.61, p<0.001$, and flow disposition, $\mathrm{r}(105)=.51, p<0.001$. Additionally, flow disposition and mindfulness were highly correlated, $\mathrm{r}(105)=.56, p<$ 0.001, which supports the first hypothesis.

A hierarchical multiple regression analysis was conducted to predict flow from demographics, history of mindfulness meditation, and cognitive flexibility and mindfulness. Demographic variables included age and gender. The first block consisted of demographic variables, and this model was not a significant predictor of flow disposition. The second block, which consisted of demographic variables and history of mindfulness meditation, was also not a good predictor of flow. Cognitive flexibility and mindfulness were added as a third block and this model was a significant predictor of flow disposition, $R^{2}=.42$, adjusted $R^{2}=.39, F(5,99)=14.30, p<.001$. From model two 
to model three, the $R^{2}$ change was .37 . In the third model, there were three significant predictors. The best predictor was mindfulness with a beta weight of .428 and was significant at the .001 level, followed by cognitive flexibility with a beta weight of .266 and was significant at the .01 level, and then history of meditation with a beta weight of .172 and was significant at the .05 level. The hierarchical regression results suggest that when gender, age, and history of mindfulness meditation are held constant cognitive flexibility and mindfulness are good predictors of flow disposition. These findings support my main hypothesis. 


\section{DISCUSSION}

The current study supports past research linking cognitive flexibility with mindfulness. However, it remains unclear if one of these skills is an antecedent of the other or if they arise simultaneously. Cognitive flexibility is characterized by creativity and freedom from cognitive rigidity whereas mindfulness is more a skill of detached, non-judgment, and attentional control. It appears as though the detached non-judgement of mindfulness may allow for the creative flexibility in cognitive flexibility.

A curious finding of the study was that history of mindfulness meditation practice did not show a strong positive correlation with mindfulness scores. However, history of mindfulness meditation practice did correlate with cognitive flexibility. It could be the case that those who are more cognitively flexible are more likely to partake in activities like mindfulness meditation. The survey question was simply "have you ever practiced mindfulness meditation?" It may be the case that there was high variability among the length and quality of the sample's meditation practice. If a participant had only minimal practice in mindfulness meditation once we might not expect for them to score high on mindfulness measures.

One weakness of the study was that only self-report measures were used to measure mindfulness, cognitive flexibility, and flow. Future research should examine the relationship between these constructs by exploring new behavioral measures.

Additionally, the sample used consisted of young college students in the United States. It may be fruitful to examine cross-cultural difference between these cognitive constructs. Also, developmental differences may play a role in mindfulness, cognitive flexibility, and flow disposition. My results showed a low correlation between age and cognitive 
flexibility, which may suggest that older adults are more cognitively flexible. This increase in cognitive flexibility with age might be associated with development into postformal ways of thinking and what Jan Sinnott (1998) calls metatheory shift.

Part of the current study was exploratory in nature because past research has not suggested a link between cognitive flexibility, as a distinct construct, and flow disposition. The results suggest that cognitive flexibility is a good predictor of the disposition toward flow. This appears to be the case because, although people have clear goals and feedback during flow state and the activities that they participate in may have strict rules or guidelines, there seems to be a need for flexibility or creativity in order to remain in flow during these activities. As the challenges and demands of an activity increase, one may need to remain cognitively flexible in order to meet these challenges and demands.

The current study also supports past research linking mindfulness and flow state. The results suggest that mindfulness can predict flow disposition. Because both mindfulness and flow require the self-regulation of attention and present moment awareness, future research should examine if these factors moderate the flow/mindfulness connection. Also, it may be beneficial to study the relationship between mindfulness meditation training and flow. If it is shown that mindfulness meditation can increase flow disposition then this type of training may be beneficial in a number of different domains.

Some have proposed that research on flow state may have implications in advancing clinical interventions (Feeney, 1996) and workplace productivity (Martin, 2004). With regard to clinical applications counselors and therapists who work with clients who suffer from depression or anxiety may benefit from utilizing positive 
intervention strategies related to flow. Some research even suggests that certain positive interventions using mediation practices may relieve symptoms of schizophrenia (Johnson, Penn, Fredrickson, Meyer, Kring, \& Brantley, 2009). Because flow state, by definition, is a state free from unpleasant emotions or cognitions, methods of eliciting this state would be extremely useful in clinical settings. Increasing mindfulness and cognitive flexibility may influence flow elicitation, but more research would need to be conducted to determine if this is true. As the current study was correlational, it could be the case that flow disposition causes increases in mindfulness and cognitive flexibility.

The current study may also have implications for organizational settings. Workers who experience flow on the job may show higher levels of productivity due to the intense focus and attention involved during the state. Future research should examine the relationship between flow disposition and workplace productivity, job satisfaction, and performance quality. If it is shown that flow relates to these factors, then recruiters and personnel selection departments may find that cognitive flexibility, mindfulness, and flow disposition questionnaires may be helpful tools in hiring practices.

\section{Conclusion}

The experience of flow, or being in the zone, can be a significant source of wellbeing (e.g. Csikszentmihayli, 1990; Fritz \& Avsec, 2007; Harari, 2008; Moneta \& Csikszentmihalyi, 1996; Myers \& Diener, 1995; Payne, Jackson, Noh, \& Stine-Morrow, 2011; Waterman, 2005). And although well-being and happiness have been discussed for at least thousands of years, research on this subject matter remains relevant today. Understanding some of the cognitive skills related to flow state may help us gain a better understanding of the good life. 
As societies become more complex and information and ideas transfers at higher speeds it is critical that people learn to acquire the skills that will allow for them to adapt and flourish in this new environment. It is my hope that this research will encourage the further development of techniques and methods that increase these cognitive skills. 


\section{APPENDICES}




\title{
APPENDIX A
}

IRB Approval Form

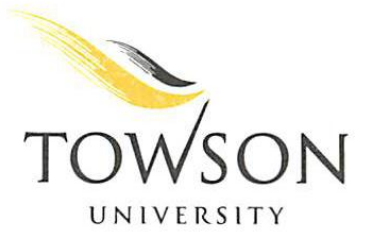

EXEMPTION NUMBER: 12-0X73

\author{
To: Bryan Moore \\ From: Institutional Review Board for the Protection of Human \\ Subjects, Melissa Osborne Groves, Member MO6/WRi \\ Date: $\quad$ Thursday, February 02, 2012 \\ RE: Application for Approval of Research Involving the Use of \\ Human Participants
}

Thank you for submitting an application for approval of the research titled, Propensity for Experiencing Flow: The Roles of Cognitive Flexibility and Mindfulness

to the Institutional Review Board for the Protection of Human Participants (IRB) at Towson University.

Your research is exempt from general Human Participants requirements according to 45 CFR 46.101(b)(2). No further review of this project is required from year to year provided it does not deviate from the submitted research design.

If you substantially change your research project or your survey instrument, please notify the Board immediately.

We wish you every success in your research project.

\section{CC: J. Sinnott}

File 


\title{
APPENDIX B
}

\author{
Consent Form
}

\section{$\underline{\text { Informed Consent }}$}

You are invited to participate in a study that examines the psychological state, Flow, and the skills related to it. Flow is a state where one feels as though they are in "the zone" and are completely focused on an enjoyable activity. The study is being conducted by Bryan Moore who is a graduate student at Towson University.

Before you decide to be a part of this study, you need to understand the risks and benefits.

If you agree to participate in this study, you will answer questions regarding your thoughts and feelings about personal Flow experiences and about how you generally think and feel. You must be at least eighteen years old to participate in this study. There should be no risk to you as a result of participating. Your decision to take part in this study is voluntary. You are free to choose whether or not you will take part in the study. If you decide to not participate, you may leave the classroom without any penalty. If you decide to participate, you may withdrawal from the study at any time, prior to submitting the survey, without any penalty. All answers will be anonymous. There will be no way to link your answers to you.

If you have any questions about this study at a later time, you may contact the principle investigator, his faculty advisor, or the chair of Towson University's Internal Review Board. Contact information will be provided to you by the researcher after the survey packet is turned in.

By beginning the survey, you will be indicating that you are eighteen years old or older, understand what is involved, and have volunteered to participate in this study. 


\section{REFERENCES}

Anderson, C. M,, Martin, M, M., \& Infante, D, A. (1998). Decision-making collaboration scale: Tests of validity. Communication Research Reports, 15, 245-255.

Baer, R.A., Smith, G.T., \& Allen, K.B. (2004). Assessment of mindfulness by self-report: The Kentucky Inventory of Mindfulness Skills. Assessment, 11, 191-206.

Baer, R. A., Smith, G. T., Hopkins, J., Krietemeyer, J., \& Toney, L. (2006). Using SelfReport Assessment Methods to Explore Facets of Mindfulness. Assessment, 13(1), 27-45. doi:10.1177/1073191105283504

Bernier, M., Thienot, E., Codron, R., \& Fournier, J. F. (2009). Mindfulness and Acceptance Approaches in Sport Performance. Journal of Clinical Sport Psychology, 3(4), 320-333. Retrieved from EBSCOhost.

Bishop, S. R. (2002). What do we really know about Mindfulness-Based Stress Reduction? Psychosomatic Medicine, 64(1), 71-83. Retrieved from EBSCOhost.

Bishop, S. R., Lau, M., Shapiro, S., Carlson, L., Anderson, N. D., Carmody, J., \& ... Devins, G. (2004). Mindfulness: A proposed operational definition. Clinical Psychology: Science and Practice, 11(3), 230-241. doi:10.1093/clipsy.bph077

Bodner, T., \& Langer, E. (2001). Individual differences in mindfulness: The Langer Mindfulness Scale. Poster session presented at the annual meeting of the American Psychological Society, Toronto, Ont., Canada.

Brown, K. W., \& Ryan, R. M. (2003). The benefits of being present: Mindfulness and its role in psychological well-being. Journal of Personality and Social Psychology, $84,822-848$.

Buchheld, N., Grossman, P., \& Walach, H. (2002). Measuring mindfulness in insight meditation (Vipassana) and meditation-based psychotherapy: The development of the Freiburg Mindfulness Inventory (FMI). Journal for Meditation and Meditation Research, 1, 11-34.

Cañas, J. J., Quesada, J. F., Antoli, A., \& Fajardo, I. (2003). Cognitive flexibility and adaptability to environmental changes in dynamic complex problem-solving tasks. Ergonomics, 46(5), 482-501. doi:10.1080/0014013031000061640

Cermakova, L., Moneta, G. B., \& Spada, M. M. (2010). Dispositional flow as a mediator of the relationships between attentional control and approaches to studying during academic examination preparation. Educational Psychology, 30(5), 495-511. doi:10.1080/01443411003777697

Chadwick,P., Hember, M., Mead, S., Lilley, B.,\&Dagnan, D. (2005). Responding mindfully to unpleasant thoughts and images: Reliability and validity of the Mindfulness Questionnaire. Unpublished manuscript.

Chan, D., \& Woollacott, M. (2007). Effects of level of meditation experience on attentional focus: Is the efficiency of executive or orientation networks improved?. The Journal of Alternative and Complementary Medicine, 13(6), 651657. doi:10.1089/acm.2007.7022

Chou, T., \& Ting, C. (2003). The role of flow experience in cyber-game addiction. Cyber Psychology \& Behavior, 6(6), 663-675. 
Clark, S. R. (2002). The impact of self-regulated attention control on the amount of time spent in flow. Dissertation Abstracts International, 63, Retrieved from EBSCOhost.

Csikszentmihalyi, M. (1990). Flow: The psychology of optimal experience. New York: Harper and Rowe.

Csikszentmihalyi, M. (2000a). Encyclopedia of psychology (vol. 3). Washington, DC: American Psychological Association.

Csikszentmihalyi, M. (2000b). Beyond boredom and anxiety. San Francisco, CA US: Jossey-Bass.

Csikszentmihalyi, M., \& Getsels, J. W. (1970). Concern for discovery: An attitudinal component of creative production. Journal of Personality, 38(1), 91-105. doi:10.1111/j.1467-6494.1970.tb00639.x

Csikszentmihalyi, M. M., \& Getzels, J. W. (1971). Discovery-oriented behavior and the originality of creative products: A study with artists. Journal of Personality and Social Psychology, 19(1), 47-52. doi:10.1037/h0031106

Dennis, J., \& Vander Wal, J.S. (2010). The Cognitive Flexibility Inventory: Instrument Development and Estimates of Reliability and Validity. Cognitive Therapy \& Research, 34(3), 241-253. Retrieved from EBSCOhost.

Derogatis, L. R. (1992). The Brief Symptom Inventory (BSI): Adminstration, scoring and procedures manual $=I I$ (2nd ed.). Minneapolis, MN: National Computer Systems.

Derryberry, D., \& Reed, M.A. (2002). Anxiety-related attentional biases and their regulation by attentional control. Journal of Abnormal Psychology, 111, 225-236.

Dunleavy, K. M. (2006). A Convergent Validity Study of the Decision-Making Collaboration Scale. North American Journal of Psychology, 8(2), 339-343. Retrieved from EBSCOhost.

Eccles, J. S., \& Wigfield, A. (2002). Motivational beliefs, values, and goals. Annual Review of Psychology, 53(1), 109-132. doi:10.1146/annurev.psych.53.100901.135153

Feeney, D. r. (1996). Purposeful self: Accessing sensory motifs as empowerment in flow states and clinical interventions. Journal of Humanistic Psychology, 36(4), 94115. doi:10.1177/00221678960364014

Feldman, G., Hayes, A., Kumar, S., Greeson, J., \& Laurenceau, J. (2007). Mindfulness and emotion regulation: The development and initial validation of the Cognitive and Affective Mindfulness Scale-Revised (CMS-R). Journal of Psychopathology and Behavioral Assessment, 29(3), 177-190. doi:10.1007/s10862-006-9035-8

Frewen, P. (2008). Letting Go: Mindfulness and Negative Automatic Thinking. Cognitive Therapy \& Research, 32(6), 758-774. Retrieved from EBSCOhost.

Fritz, B., \& Avsec, A. (2007). The experience of flow and subjective well-being of music students. Psihološka Obzorja/Horizons of Psychology, 16(2), 5-17.

Gratz, K. L.,\&Roemer, L. (2004). Multidimensional assessment of emotion regulation and dysregulation: Development, factor structure, and initial validation of the difficulties in emotion regulation scale. Journal of Psychopathology and Behavioral Assessment, 26, 41-54. 
Harari, Y. (2008). Combat flow: Military, political, and ethical dimensions of subjective well-being in war. Review of General Psychology, 12(3), 253-264. doi:10.1037/1089-2680.12.3.253

Hirt, E. R., Devers, E. E., \& McCrea, S. M. (2008). I want to be creative: Exploring the role of hedonic contingency theory in the positive mood-cognitive flexibility link. Journal of Personality and Social Psychology, 94(2), 214-230. doi:10.1037/00223514.94.2.94.2.214

Infante, D. A., \& Rancer, A. S. (1982). A conceptualization and measure of argumentativeness. Journal of Personality Assessment, 46(1), 72-80. doi:10.1207/s15327752jpa4601_13

Jackson, S.A., \& Eklund, R.C. (2002). Assessing flow in physical activity: The flow state scale-2 and dispositional flow scale-2. Journal of Sport \& Exercise Psychology, 24, 133-150.

Jackson, S.A., \& Eklund, R.C. (2004). The flow scale manual. Morgantown, WV: Fitness Information Technology, Inc.

Jackson, S. A., \& Marsh, H. (1996). Development and validation of a scale to measure optimal experience: The Flow State Scale. Journal of Sport \& Exercise Psychology, 18(1), 17-35. Retrieved from EBSCOhost.

Jackson, S. A., Martin, A. J., \& Eklund, R. C. (2008). Long and short measures of flow: The construct validity of the FSS-2, DFS-2, and new brief counterparts. Journal of Sport \& Exercise Psychology, 30(5), 561-587. Retrieved from EBSCOhost.

Jensen, C., Vangkilde, S., Frokjaer, V., \& Hasselbalch, S. G. (2011). Mindfulness training affects attention —or is it attentional effort? Journal of Experimental Psychology: General, doi:10.1037/a0024931

Johnson, D. P., Penn, D. L., Fredrickson, B. L., Meyer, P. S., Kring, A. M., \& Brantley, M. (2009). Loving-kindness meditation to enhance recovery from negative symptoms of schizophrenia. Journal of Clinical Psychology, 65(5), 499-509. doi:10.1002/jclp.20591

Kabat-Zinn, J. (2003). Mindfulness-based interventions in context: Past, present, and future. Clinical Psychology: Science and Practice, 10(2), 144-156. doi:10.1093/clipsy/bpg016

Kabat-Zinn, J. (2005). Coming to our senses. New York: Hyperion.

Kee, Y., \& Wang, C. (2008). Relationships between mindfulness, flow dispositions and mental skills adoption: A cluster analytic approach. Psychology of Sport and Exercise, 9(4), 393-411. doi:10.1016/j.psychsport.2007.07.001

Kumar, S. M. (2005). Grieving Mindfully: A Compassionate And Spiritual Guide To Coping With Loss. Oakland, CA: New Harbinger.

Langer, E. J. (1992). Matters of mind: Mindfulness/mindlessness in perspective. Consciousness and Cognition: An International Journal, 1(4), 289-305. doi:10.1016/1053-8100(92)90066-J

Larson, R., \& Csikzentmihalyi, M. (1983). The experience sampling method. In H. T. Reis (Ed.), Naturalistic Approaches to Studying Interaction (pp. 41-57). San Francisco: Jossey-Bass. 
Martin, A. J. (2004). The Role of Positive Psychology in Enhancing Satisfaction, Motivation, and Productivity in the Workplace. Journal of Organizational Behavior Management, 24(1-2), 113-133. doi:10.1300/J075v24n01_07

Martin, M. M., Anderson, C. M., \& Thweatt, K. S. (1998). Aggressive Communication Traits and Their Relationships with the Cognitive Flexibility Scale and the Communication Flexibility Scale. Journal of Social Behavior \& Personality, 13(3), 531-540. Retrieved from EBSCOhost.

Martin, M. M., \& Rubin, R. B. (1995). A new measure of cognitive flexibility. Psychological Reports, 76(2), 623-626. Retrieved from EBSCOhost.

Martin, M. M., Staggers, S.M., \& Anderson, C. M. (2011): The Relationships Between Cognitive Flexibility with Dogmatism, Intellectual Flexibility, Preference for Consistency, and Self-Compassion. Communication Research Reports, 3(28), 275-280. doi:http://dx.doi.org/10.1080/08824096.2011.587555

Martin, A.J., Tipler, D.V., Marsh, H.W., Richards, G.E., \& Williams, M.R. (2006). Assessing multidimensional physical activity motivation: A construct validity study of highschool students. Journal of Sport \& Exercise Psychology, 28, 171192.

Mayer, J. L.,\&Farmer, R. F. (2003). The development and psychometric evaluation of a new measure of dissociative activities. Journal of Personality Assessment, 80, 185-196.

Meresko, R., Rubin, M., Shontz, F. C., \& Morrow, W. R. (1954). Rigidity of attitudes regarding personal habits and its ideological correlates. The Journal of Abnormal and Social Psychology, 49(1), 89-93. doi:10.1037/h0056505

Moneta, G. B., \& Csikszentmihalyi, M. (1996). The effect of perceived challenges and skills on the quality of subjective experience. Journal of Personality, 64(2), 275310. doi:10.1111/j.1467-6494.1996.tb00512.x

Moore, A., \& Malinowski, P. (2009). Meditation, mindfulness and cognitive flexibility. Consciousness and Cognition: An International Journal, 18(1), 176-186. doi:10.1016/j.concog.2008.12.008

Murray, N., Sujan, H., Hirt, E. R., \& Sujan, M. (1990). The influence of mood on categorization: A cognitive flexibility interpretation. Journal of Personality and Social Psychology, 59(3), 411-425. doi:10.1037/0022-3514.59.3.411

Myers, D. G., \& Diener, E. (1995). Who is happy?. Psychological Science, 6(1), 10-19. doi:10.1111/j.1467-9280.1995.tb00298.x

Payne, B. R., Jackson, J. J., Noh, S., \& Stine-Morrow, E. L. (2011). In the zone: Flow state and cognition in older adults. Psychology and Aging, 26(3), 738-743. doi:10.1037/a0022359

Privette, G. (1983). Peak experience, peak performance, and flow: a comparative analysis of positive human experiences. Journal of Personality and Social Psychology, 45(6), 1361-1368.

Reiss, S. (2000). Human individuality, happiness, and flow. American Psychologist, 55(10), 1161-1162. doi:10.1037/0003-066X.55.10.1161

Ryan, R. M., \& Deci, E. L. (2001). On happiness and human potentials: A review of research on hedonic and eudaimonic well-being. Annual Review of Psychology, 52141-166. doi:10.1146/annurev.psych.52.1.141 
Scoresby, J., \& Shelton, B. E. (2011). Visual perspectives within educational computer games: Effects on presence and flow within virtual immersive learning environments. Instructional Science, 39(3), 227-254. doi:10.1007/s11251-0109126-5

Shapiro, S. L., Carlson, L. E., Astin, J. A., \& Freedman, B. (2006). Mechanisms of Mindfulness. Journal of Clinical Psychology, 62(3), 373-386. doi:10.1002/jclp.20237

Sinnott, J. D. (1998). The development of logic in adulthood: Postformal thought and its applications. New York: Plenum Press.

Stavrou, N. A., Jackson, S. A., Zervas, Y., \& Karteroliotis, K. (2007). Flow experience and athletes' performance with reference to the orthogonal model of flow. The Sport Psychologist, 21(4), 438-457. Retrieved from EBSCOhost.

Tang, Y. Y., Ma, Y., Wang, J., Fan, Y., Feng, S., Lu, Q. et al. (2007). Short-term meditation training improves attention and self-regulation. Proceedings of the National Academy of Sciences, USA, 104, 17152-17156.

van den Hurk, P. P. (2010). Greater efficiency in attentional processing related to mindfulness meditation. Quarterly Journal of Experimental Psychology, 63(6), 1168-1180. Retrieved from EBSCOhost.

Walach, H., Buchheld, N., Buttenmüller, V., Kleinknecht, N., \& Schmidt, S. (2006). Measuring mindfulness: the Freiburg Mindfulness Inventory (FMI). Personality and Individual Differences, 40(8), 1543-1555. doi:10.1016/j.paid.2005.11.025

Wang, C., Khoo, A., Liu, W., \& Divaharan, S. (2008). Passion and intrinsic motivation in digital gaming. CyberPsychology \& Behavior, 11(1), 39-45. doi:10.1089/cpb.2007.0004

Wang, C., Liu, W. C., \& Khoo, A. A. (2009). The psychometric properties of Dispositional Flow Scale-2 in Internet gaming. Current Psychology: Research \& Reviews, 28(3), 194-201. doi:10.1007/s12144-009-9058-X

Waterman, A. S. (1993). Two conceptions of happiness: Contrasts of personal expressiveness (eudaimonia) and hedonic enjoyment. Journal of Personality and Social Psychology, 64(4), 678-691. doi:10.1037/0022-3514.64.4.678

Waterman, A. S. (2005). When effort is enjoyed: Two studies of intrinsic motivation for personally salient activities. Motivation and Emotion, 29(3), 165-188. doi:10.1007/s11031005-9440-4

Waterman, A. S., Schwartz, S. J., \& Conti, R. (2008). The implications of two conceptions of happiness (hedonic enjoyment and eudaimonia) for the understanding of intrinsic motivation. Journal of Happiness Studies, 9(1), 41-79. doi:10.1007/s10902-006-9020-7

Wright, J. J., Sadlo, G., \& Stew, G. (2006). Challenge-skills and mindfulness: An exploration of the conundrum of flow process. OTJR: Occupation, Participation and Health, 26(1), 25-32. Retrieved from EBSCOhost.

Wright, J. J., Sadlo, G., \& Stew, G. (2007). Further explorations into the conundrum of flow process. Journal of Occupational Science, 14(3), 136-144. Retrieved from EBSCOhost. 
Yuan, Q., Hu, J., \& Wang, Y. (2009). A study on psychometric properties of Chinese version of Flow State Scale in Chinese college students. Chinese Journal of Clinical Psychology, 17(5), 559-561. Retrieved from EBSCOhost. 


\section{Bryan Moore \\ Curriculum Vitae \\ Johns Hopkins University School of Medicine 550 N. Broadway, Suite 103 \\ Baltimore, MD 21205 \\ Email-bmoore8@students.towson.edu}

\section{$\underline{\text { EDUCATION }}$}

2008-present $\quad$ M.A. (expected May 2012)

Towson University, Towson, MD

Experimental Psychology

2007

B.A.

Winthrop University, Rock Hill, SC

Major: Psychology

Minor: Philosophy and Religious Studies

\section{EMPLOYMENT HISTORY}

Johns Hopkins University, Baltimore, MD Feb. 2010 - Present

Research Assistant: Integrated Program for Substance Abuse Research

- Conducts alcohol laboratory sessions and coordinates MRI and PET imaging procedures. Responsible for maintaining subject enrollment logs, data entry, and data quality checks. Conducts telephone screening and procedure scheduling. Administers subjective report questionnaires and assessments.

Walgreens Co., Columbia, SC and Baltimore, MD Dec. 2003 - Feb 2010 Assistant Manager

- Supervised employees and ensured completion of store-level, corporate, initiatives. Conducted employment interviews. Maintained bookkeeping and inventory maintenance. Provided customer service and merchandising strategies.

United Way of York County, SC, Rock Hill, SC I Jan. 2007 - May 2007 Special Projects Coordinator / Marketing Intern

- Wrote and distributed press releases. Web support and data entry. Performed administrative duties and obtained project sponsorship. Provided media relations.

\section{AWARDS RECEIVED}

Dean's List - Winthrop University, 2005 and 2006

Pi Gamma Mu - International Honor Society in Social Sciences

Psi Chi - The National Honor Society in Psychology

Undergraduate Scholars Award - Winthrop University, 2007 


\section{PRESENTATIONS}

Moore, B.A. (2012). Propensity for experiencing flow: The roles of cognitive flexibility and mindfulness. Paper presented at the Towson University Student Research \& Scholarship Expo, Towson, MD.

Moore, B.A. (2012). In the flow while at the peak: An overlap in optimal experience. Poster presented at the 2012 Maryland Psychological Association's Graduate Students' Convention, Columbia, MD.

Moore, B.A., Mason, T., \& Sleigh-Ritzer, M.J. (2007). The relationship between young adults' mystical experiences and attitudes toward the value of life. Poster presented at the 2007 Southeastern Psychological Association Annual Convention, New Orleans, LA.

\section{MANUSCRIPTS UNDER REVIEW}

Moore, B.A. (Book chapter under review) Flow theory and the paradox of happiness. Adult Motivation and Positive Psychology (ed. book).

\section{GRADUATE COURSEWORK}

- Biological Psychology

- Cognitive Psychology

- Experimental Design I

- Experimental Design II

- Independent Investigation in Psychology: Meaning in Life

- Motivation

- Multivariate Methods

- Research Methods

- Social Psychology

\section{WORKSHOPS ATTENDED}

- Frontiers of Trauma Treatment, Bessel van der Kolk, MD. American Psychological Association Annual Convention, Washington, D.C. Aug. 2011. (3 Credit hours).

- Positive Psychology and Psychodynamic Therapy, Richard Summers, MD. Second World Congress on Positive Psychology, Philadelphia, PA. July 2011.

- Fundamentals for the Research Coordinator, The Institute for Johns Hopkins Nursing. June 2011. (18.2 credit hours approved by Society of Clinical Research Associates and the Association of Clinical Research Professionals).

\section{PROFESSIONAL AFFILIATIONS}

- American Psychological Association 
- American Psychological Association of Graduate Students

- Maryland Psychological Association

- Society for Industrial and Organizational Psychology, Inc 
